\section{PRODUÇÃO ACADÊMICA EM FUTEBOL E FUTSAL FEMININO: ESTADO DA ARTE DOS ARTIGOS CIENTÍFICOS NACIONAIS NA ÁREA DA EDUCAÇÃO FÍSICA}

\author{
ACADEMIC RESEARCH ON WOMEN'S FOOTBALL AND FUTSAL: THE \\ CURRENT STATE OF SCIENTIFIC ARTICLES IN PHYSICAL EDUCATION
}

PRODUCCIÓN ACADÉMICA EN FÚTBOL Y FUTSAL FEMENINO: ESTADO DEL ARTE DE ARTÍCULOS CIENTÍFICOS BRASILEÑOS EN EL ÁREA DE LA EDUCACIÓN FÍSICA

\author{
Júlia Barreira*, Maria Camila Rodrigues Gonçalves*, \\ Daniele Cristina Carqueijeiro de Medeiros*, Larissa Rafaela Galatti*
}

\begin{abstract}
Palavras chave:
Futebol.

Mulheres.

Educação Física.

Bibliometria.

Resumo: Este estudo tem como objetivo mapear a produção de artigos científicos nacionais sobre futebol e futsal feminino. Analisamos 38 periódicos da área da Educação Física, indexados pela Qualis Capes na área 21, que publicam estudos relacionados a esportes. Os 76 artigos encontrados foram enquadrados em nove categorias e divididos por ano de publicação. Os resultados mostraram que as primeiras publicações ocorreram no final da década de 1990, com um aumento significativo a partir do ano de 2008. Nesse mesmo período foi criada a Revista Brasileira de Futsal e Futebol, principal veículo de publicação sobre as modalidades. Encontramos uma distribuição homogênea de homens e mulheres como primeiros autores, sendo a coautoria majoritariamente masculina. Verificamos que os estudos sobre gênero representam, aproximadamente, um terço de toda a publicação sobre as modalidades. Esse resultado reforça a importância da discussão sobre 0 empoderamento feminino para o desenvolvimento do futebol e futsal feminino.
\end{abstract}

Keywords:

Football.

Women.

Physical Education.

Bibliometrics.

Palabras clave:

Fútbol.

Mujeres.

Educación Física.

Bibliometría.
Abstract: This study analyzes Brazilian articles on women's football and futsal. It examined 38 national Physical Education journals indexed under Qualis Capes in area 21 , which publish sports-related studies. We found 76 articles that were classified in nine categories and divided by year of publication. The results showed that the first publications occurred at the end of the 90's and a significant increase took place after 2008. The Brazilian Journal of Futsal and Football - the main journal on those sports - was created in the same period. We found a homogeneous distribution between male and female first authors while co-authorship was mostly male. Gender studies represent about one third of all articles on women's football. This reinforces the importance of the discussion about women's empowerment for female football and futsal development.

Resumen: Este estudio tiene como objetivo mapear y analizar la producción de artículos científicos brasileños sobre fútbol y futsal femenino. Buscamos las publicaciones en 38 periódicos nacionales del área de Educación Física que publican estudios relacionados al deporte. Los 76 artículos encontrados fueron encuadrados en 9 categorías y divididos por año de publicación. Los resultados mostraron que las primeras publicaciones ocurrieron a finales de la década de 1990, con un aumento significativo a partir del año 2008. En ese mismo período se creó la Revista Brasileña de Fútbol Sala y Fútbol, principal vehículo de publicación sobre la modalidad. Encontramos una distribución homogénea entre primeros autores hombres y mujeres, aunque la coautoría es mayoritariamente masculina. Verificamos que los estudios sobre género representan, aproximadamente, un tercio de toda la publicación sobre la modalidad. Este resultado refuerza la importancia de la discusión sobre el empoderamiento femenino para el desarrollo del fútbol y futsal femenino.
*Universidade Estadual de Campinas. Campinas, SP, Brasil. E-mail: jubarreira2@ hotmail.com; maria.camiila@hotmail.com; danieli_ccm@hotmail.com; lagalatti@ hotmail.com

Recebido em: 31-01-2018 Aprovado em: 07-05-2018

DOI: http://dx.doi.org/10.22456/1982-8918.80030 (c) (1) (8) Licence 


\section{INTRODUÇÃO}

O futebol e o futsal, esportes populares e amplamente praticados no Brasil, ainda são marcados por diferenças abissais de gênero quando se trata da participação feminina. Ainda que 0 acesso das mulheres a essas e outras modalidades tenha aumentado no cenário brasileiro contemporâneo ${ }^{1}$, as praticantes ainda são submetidas a padrões e modelos seculares, especialmente voltados à construção de estereótipos ligados ao corpo e à sexualidade.

O início do século XX, período em que os esportes se estruturavam e se constituíam no País, foi marcado por amplos embates a respeito da participação feminina. Os mais progressistas seduziam as praticantes pontuando os benefícios médicos e morais da prática esportiva, além do prazer gerado pela atividade física. Os discursos mais moralistas tratavam de aconselhar apenas práticas que estabeleciam uma relação entre mulher, feminilidade e beleza, ou que reforçavam as características geralmente atreladas às mulheres, como a fragilidade, a docilidade e o sentimentalismo (GOELLNER, 2005; SOUSA; ALTMANN, 1999).

Ficava claro, para os discursos médicos e políticos do início do século XX, que o futebol não era adequado às qualidades femininas desejadas na prática esportiva; pelo contrário, a modalidade era capaz de "masculinizar" as mulheres e machucar seus órgãos reprodutivos (SOUSA; ALTMANN, 1999). Essas representações foram reforçadas pelo Decreto $n-7$, publicado pelo Conselho Nacional de Desportos em 1965, que proibia as mulheres de praticarem algumas modalidades esportivas, dentre elas o futebol e futebol de salão²2 (GOELLNER, 2005).

A proibição legal foi revogada em 1979. Entretanto, a prática esportiva brasileira não se tornou menos generificada, e tampouco mais igualitária (SOUSA; ALTMANN, 1999). Em 1999, apenas $0,7 \%$ das mulheres moradoras da cidade do Rio de Janeiro praticavam futebol no seu tempo de lazer (SALLES-COSTAS et al., 2003). Quase 20 anos depois, um estudo realizado pelo Ministério do Esporte (2013) revelou que, aproximadamente, 5\% das mulheres brasileiras praticam futebol e $1 \%$ pratica futsal em momentos de lazer.

As concepções apresentadas acima, unidas à proibição legal, geraram condições desiguais de acesso e participação esportiva aos homens e às mulheres. Ainda que as mulheres tenham transgredido as regras e as proibições da época (GOELLNER, 2005; MOURÃO; MOREL, 2005), a participação esportiva feminina no Brasil foi menor que a masculina, especialmente no que tange às modalidades de futebol e futsal. As consequências também se estenderam ao campo científico, no qual os primeiros estudos sobre futebol feminino foram publicados somente no final da década de 1990. Os preconceitos e desafios enfrentados pelas mulheres também refletiram em um aumento de publicações sobre gênero, futebol e futsal feminino nas últimas duas décadas (ANJOS; DANTAS, 2016). Entretanto, até o presente momento, desconhecemos o espaço ocupado pelas mulheres como autoras e coautoras desses estudos.

Identificamos quatro estudos de revisão bibliográfica que analisaram a publicação científica nacional sobre futebol feminino nas últimas décadas. Viana (2008) investigou artigos publicados sobre gênero na prática pedagógica do futebol. 0 estudo teve como objetivo analisar a construção cultural do corpo feminino e verificar os preconceitos associados às questões de gênero quanto à prática do futebol feminino no Brasil. Feltrin et al. (2012)

1 Nos Jogos Olímpicos de 1980 as mulheres representavam aproximadamente 10\% da delegação brasileira. Duas décadas depois, as mulheres representavam 40\% da delegação brasileira nos Jogos Olímpicos de Sidney (2000) (SOUZA; KNIJNIK, 2007). 
realizaram um levantamento de estudos que investigaram e caracterizaram as praticantes de futebol feminino no País. Teixeira e Caminha (2013) analisaram a existência do preconceito de gênero no futebol feminino à luz da literatura científica e discutiram os aspectos socioculturais que os fundamentam. Salvini et al. (2014) analisaram a produção científica dentro do contexto universitário. Para isso, os autores mapearam as teses e dissertações produzidas sobre futebol feminino no período de 1990 a 2010. Nenhum estudo de revisão bibliográfica foi encontrado em relação ao futsal feminino.

As revisões citadas acima, embora bastante relevantes para o conhecimento a respeito da temática, analisaram questões pontuais relacionadas ao futebol feminino. Não é possível identificar, através dos trabalhos citados, a totalidade de artigos sobre o futebol e futsal feminino no Brasil, ou questões como: quais os principais assuntos investigados, como se distribui a participação de mulheres e homens como autores e pesquisadores desta temática e qual o comportamento das publicações ao longo dos últimos anos. O conhecimento sobre a produção científica nacional no formato de artigos é importante para refletirmos sobre as discussões e avanços promovidos nas modalidades e apontar lacunas científicas a serem preenchidas por estudos futuros.

A fim de mapear e discutir a produção científica nacional sobre futebol e futsal feminino, buscamos por uma metodologia denominada de "estado da arte" ou "estado do conhecimento". Definido como de caráter bibliográfico, esse método traz o comum desafio de mapear e de discutir certa produção acadêmica em diferentes campos do conhecimento, tentando responder que aspectos e dimensões vêm sendo destacados e privilegiados em diferentes épocas e lugares (FERREIRA, 2002).

A partir dessa metodologia, o objetivo deste trabalho é mapear a produção científica sobre futebol feminino e futsal ${ }^{3} \mathrm{em}$ periódicos nacionais. Como objetivos específicos, buscamos analisar a periodicidade de artigos sobre futebol feminino e futsal ao longo dos anos; analisar, dentro deste universo, quais foram as temáticas mais investigadas nos artigos encontrados; analisar quais os periódicos que possuem maior frequência de publicações sobre futebol e futsal feminino; e, por fim, compreender de que forma as mulheres e homens participaram como autores e coautores destes trabalhos.

\section{MATERIAIS E MÉTODOS}

Com a finalidade de delimitar o universo explorado pelo estudo, identificamos todos os periódicos nacionais indexados pela Qualis Capes na área 21 que publicam estudos relacionados a esportes. Encontramos 38 periódicos classificados de C a A1 pelo Qualis Capes (2013-2016). Desse total, dois periódicos não apresentaram frequência de publicação nos últimos anos, sendo excluídos do estudo. Uma revista apresentou apenas resumos e trabalhos publicados em anais de congresso, por esse motivo também foi excluída. Ao final, 35 periódicos nacionais foram investigados 4 .

\footnotetext{
3 Embora o futebol e o futsal sejam duas práticas distintas, com diferentes exigências técnicas, táticas e físicas, as modalidades apresentam semelhanças no que tange às barreiras e aos impedimentos vivenciados pelas mulheres na prática esportiva. Dado que o futebol e o futsal representam o mesmo fenômeno aqui estudado, ambas as modalidades foram analisadas nos artigos selecionados.

4 Compreendemos a distinção existente entre as revistas aqui analisadas. As revistas possuem percursos, focos e fatores Qualis bastante distintos umas das outras, o que leva a diferentes possibilidades e periodicidades de publicação. Entretanto, reconhecemos a necessidade de realizar uma análise que englobasse todas as revistas da área 21 que publicam estudos relacionados aos esportes e que permitisse alcançar um amplo panorama das publicações sobre futebol e futsal feminino. Esse panorama ampliado é o que distingue a pesquisa aqui realizada de
} 
A coleta dos artigos foi feita utilizando as palavras-chave futebol, futsal, feminino e mulheres. Os artigos que tivessem esses termos no seu título, resumo ou palavras-chave foram selecionados para as análises. Com o objetivo de abranger ao máximo o levantamento realizado, não estabelecemos limite inferior para a data de publicação dos artigos. 0 limite superior foi estabelecido até a data da última coleta realizada, em dezembro de 2017. Neste estudo foram considerados apenas artigos originais e revisões da literatura. Entre os artigos selecionados, uma resenha e um ponto de vista foram retirados e resumos publicados em congressos não foram considerados. Alguns estudos utilizavam atletas de futebol feminino como amostra, e não como objeto de estudo, sendo também excluídos do trabalho.

Após a seleção dos artigos, eles foram categorizados, sendo divididos nos anos em que foram publicados e nas temáticas investigadas. Para isso, utilizamos nove categorias de classificação que serão detalhadas a seguir ${ }^{5}$. Os títulos, palavras-chave e resumos foram utilizados para definir a categoria dos artigos; quando insuficientes, realizamos a leitura completa dos artigos. A categorização de cada artigo foi feita por dois avaliadores. Quando não houve concordância entre eles, um terceiro avaliador também realizou a classificação. Os critérios utilizados na classificação dos artigos são apresentados abaixo:

- Treinamento: estudos que investigaram aspectos relacionados ao treinamento físico, técnico e tático das modalidades. Nessa categoria também foram considerados artigos que analisaram variáveis técnicas e táticas durante as partidas.

- Carreira Esportiva: artigos que analisaram a história profissional das atletas durante sua iniciação e formação nas modalidades. Os estudos investigaram local e idade de iniciação, a influência da família e os recursos físicos disponíveis nesse processo de desenvolvimento.

- Gênero: estudos que investigaram e debateram as dificuldades, discriminações e preconceitos vivenciados pelas mulheres no contexto do futebol e do futsal relacionados às questões de gênero.

- História: artigos que analisaram o futebol e o futsal feminino no passado em espaços de tempo definidos.

- Psicologia: artigos que realizaram análises descritivas sobre o perfil psicológico ou que realizam intervenções psicológicas com atletas de futebol e futsal feminino.

- Sociologia: estudos que investigaram a migração de atletas para fora do país; estudos que se valem da etnografia e de autores da Sociologia como forma de apropriação e investigação da temática.

- Mídia: estudos que analisaram a cobertura de eventos ou assuntos relacionados ao futebol e ao futsal feminino por diferentes veículos de comunicação.

- Fisiologia: estudos que caracterizaram as demandas fisiológicas da partida ou que avaliaram as capacidades físicas e composição corporal das atletas. Nessa categoria também foram considerados os artigos sobre 0 efeito da idade relativa nas modalidades devido ao enfoque biológico dado à temática.

outras já feitas, e, assim, a torna original. É esse aspecto também que faz com que ela contribua com pesquisas posteriores que se disponham a analisar esta temática.

5 Os artigos supracitados foram analisados e delimitados em uma das categorias de análise descritas neste trabalho. Embora marcadas com certo rigor de definição, as categorias destacadas dialogam entre si em alguns dos trabalhos mencionados, sendo escolhida a de maior proeminência a partir dos artigos analisados. A categoria gênero, por exemplo, englobou diversos eixos de discussão, como "Educação Física Escolar", "lazer", "mídia". Ainda assim, os artigos permaneceram inseridos nesta categoria pois compreendemos que o principal eixo de análise, mesmo que as discussões perpassem outras temáticas, são sobretudo as questões de gênero. 
- Literatura: artigos de revisão de literatura sobre o futebol e o futsal feminino no ambiente escolar, de rendimento ou relacionados às questões de gênero.

Após esta etapa, organizamos os resultados em uma planilha do Microsoft Office Excel para posterior análise. A estatística descritiva, baseada em frequências absolutas e relativas, foi utilizada para resumir o banco de dados coletados ${ }^{6}$.

\section{RESULTADOS}

Ao todo foram encontrados 76 artigos, 59sobre futebol e 17 sobre futsal feminino, publicados em 20 periódicos. Essa quantidade representa $57 \%$ dos periódicos nacionais indexados pela Capes (área 21) que publicam estudos relacionados aos esportes.

A Tabela 1 apresenta a quantidade de artigos sobre futebol e futsal feminino encontrada nas revistas investigadas. A Revista Brasileira de Futsal e Futebol apresentou o maior número (18\%) de artigos publicados sobre o tema, seguida da Revista Brasileira de Medicina do Esporte (11\%), a Revista Brasileira de Ciência do Esporte (8\%) e a Movimento (8\%).

Tabela 1 - Quantidade de artigos sobre futebol e futsal feminino encontrados nas revistas investigadas.

\begin{tabular}{lccc}
\hline \multicolumn{1}{c}{ Título da revista } & $\begin{array}{c}\text { Estrato Qualis } \\
(\mathbf{2 0 1 3}-\mathbf{2 0 1 6})\end{array}$ & $\begin{array}{c}\text { Frequência } \\
\text { Absoluta }\end{array}$ & $\begin{array}{c}\text { Frequência } \\
\text { Relativa }\end{array}$ \\
\hline Praxia & B4 & 1 & $1 \%$ \\
Revista Brasileira de Atividade Física e Saúde & B2 & 1 & $1 \%$ \\
Temas em Educação Física Escolar & B5 & 1 & $1 \%$ \\
Coleção Pesquisa em Educação Física & B4 & 2 & $3 \%$ \\
Licere & B2 & 2 & $3 \%$ \\
Recorde: Revista de História do Esporte & B4 & 2 & $3 \%$ \\
Revista Brasileira de Ciência e Movimento & B2 & 2 & $3 \%$ \\
Revista Brasileira de Cineantropometria e Desempenho Humano & B1 & 2 & $3 \%$ \\
Revista da Educação Física & B1 & 2 & $3 \%$ \\
Kinesis & B4 & 3 & $4 \%$ \\
Motriz & B1 & 3 & $4 \%$ \\
Conexões & B4 & 4 & $5 \%$ \\
Motrivivência & B2 & 4 & $5 \%$ \\
Pensar a Prática & B2 & 4 & $5 \%$ \\
Revista Brasileira de Educação Física e Esporte & B1 & 4 & $5 \%$ \\
Esporte e Sociedade & B4 & 5 & $7 \%$ \\
Movimento & A2 & 6 & $8 \%$ \\
Revista Brasileira de Ciências do Esporte & B1 & 6 & $8 \%$ \\
Revista Brasileira de Medicina do Esporte & A2 & 8 & $11 \%$ \\
Revista Brasileira de Futsal e Futebol & B4 & 14 & $18 \%$ \\
\hline Total & & 76 & $100 \%$ \\
\hline
\end{tabular}

Fonte: Elaborado pelas autoras.

A Figura 1 apresenta as datas de publicações dos artigos. Os primeiros artigos publicados sobre o tema datam de 1998. Vemos que a frequência de publicações foi crescente

6 Por se tratar de uma pesquisa realizada com materiais públicos e de livre acesso, não houve a submissão do trabalho ao Comitê de Ética e nem a assinatura do Termo de Consentimento Livre e Esclarecido. 
ao longo dos anos, apresentando um grande aumento na quantidade de publicações a partir de 2008.

Figura 1 - Quantidade de artigos publicados sobre futebol e futsal feminino ao longo dos anos.

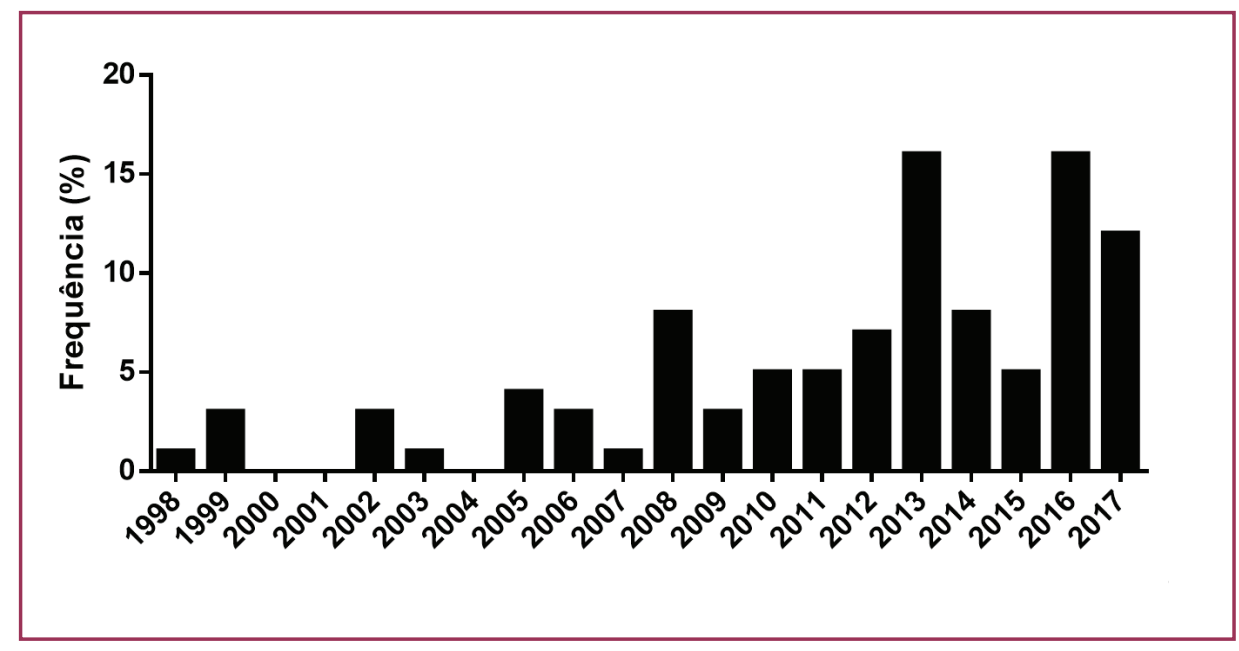

Fonte: Elaborado pelas autoras.

A Figura 2 apresenta a frequência de artigos publicados sobre cada tema. Podemos observar que o tema mais frequente nos artigos sobre futebol e futsal feminino é o gênero, seguido por fisiologia e história. Os dois temas menos encontrados nos artigos estudados foram carreira esportiva, sociologia e mídia.

Figura 2 - Classificação dos artigos encontrados sobre futebol e futsal feminino por tema.

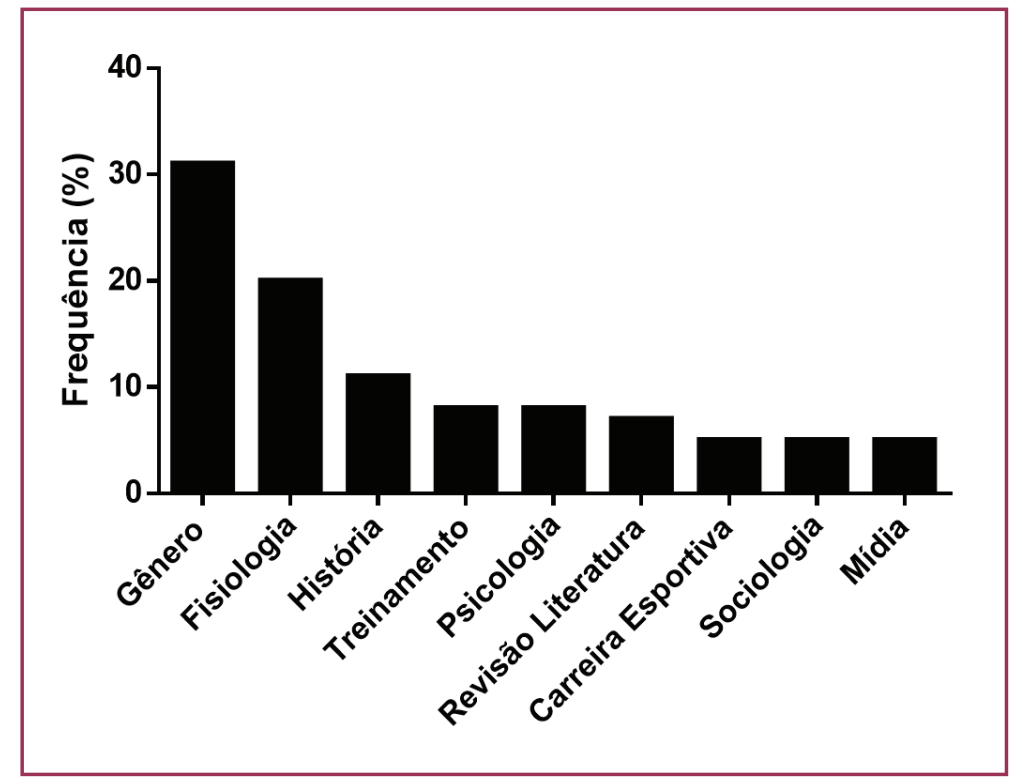

Fonte: Elaborado pelas autoras.

A Tabela 2 apresenta a quantidade de artigos produzidos por homens e mulheres. Verificamos que como primeiro autor existe uma distribuição homogênea entre homens e mulheres. Já em relação aos coautores, vemos o predomínio da participação masculina. 
Tabela 2 - Quantidade de artigos sobre futebol e futsal feminino produzidos por homens e mulheres.

\begin{tabular}{lcc}
\hline & Primeiro autor(a) & Coautores(as) \\
\hline Mulheres & $40(53 \%)$ & $57(37 \%)$ \\
Homens & $36(37 \%)$ & $96(63 \%)$ \\
\hline Total & $76(100 \%)$ & $153(100 \%)$ \\
\hline
\end{tabular}

Fonte: Elaborado pelas autoras.

\section{DISCUSSÃO}

Os resultados desse levantamento apontam que a discussão sobre futebol e futsal feminino nos artigos nacionais de Educação Física é bastante recente. 0 primeiro artigo encontrado foi publicado apenas em 19987. Da mesma forma, Salvini, Ferreira e Marchi Júnior (2014), ao mapear as teses e dissertações sobre o futebol feminino no campo acadêmico brasileiro verificaram que a primeira dissertação defendida sobre o assunto data de $1997^{8}$. Diversos fatores podem explicar o início das publicações sobre as modalidades somente no final do século XX. A principal hipótese é a de que a conjuntura social e determinantes legais como as legislações proibitivas - postergaram o desenvolvimento das modalidades na prática, o que produziu ecos na investigação científica a respeito das modalidades, já que as primeiras publicações foram feitas quase duas décadas após o fim dos impedimentos legais.

O período de silenciamento em relação ao futebol feminino foi interrompido pelos eventos internacionais que aconteceram na década de 1990. Em 1991 foi realizada a primeira edição da Copa do Mundo de Futebol Feminino, na China, e em 1996 a modalidade se torna olímpica nos Jogos de Atlanta. Esses eventos aumentaram a visibilidade do esporte no mundo. Como consequência, mais de 2.000 artigos científicos internacionais publicados sobre a modalidade foram publicados a partir da década de 1990 (DATSON, 2014). Provavelmente, a participação brasileira nessas importantes competições internacionais também aumentou a popularidade do futebol feminino nacionalmente, assim como o interesse dos pesquisadores pelo esporte.

Como pode ser observado na Figura 1, verificamos um aumento significativo de publicações nacionais a partir do ano de 2008. Diversos motivos podem explicar esse resultado. 0 primeiro motivo é o bom desempenho das seleções brasileiras em competições internacionais de futebol e futsal a partir dos anos 2000. A seleção brasileira de futebol feminino teve seu melhor desempenho olímpico nas edições de 2004 e 2008, conquistando a medalha de prata nas duas edições consecutivas. As medalhas de ouro ficaram com a seleção dos Estados Unidos, maior campeã da modalidade. A seleção de futsal foi campeã por seis anos consecutivos do Torneio Mundial de Futsal Feminino (2010-2015). Outro fator que pode ter influenciado o aumento de publicações foi a vitória da seleção brasileira de futebol nos Jogos Pan-Americanos de 2007, realizado no Brasil. Além disso, os anos 2000 foram marcados pelo fato inédito da jogadora de futebol da seleção brasileira Marta ganhar o título de melhor do mundo por cinco anos consecutivos (2006-2011).

\footnotetext{
7 Artigo "Assimetrias laterais no desempenho de habilidades motoras relacionadas ao futebol", publicado na revista Kinesis por Luis Augusto Teixeira e colaboradores. 0 estudo teve como objetivo analisar e comparar as habilidades motoras de praticantes de futebol feminino e masculino. Embora o trabalho não seja exclusivamente sobre futebol feminino, ele apresenta uma primeira análise sobre as habilidades técnicas das praticantes da modalidade.

80 título da dissertação, de autoria de Lúcia da Costa Leite Reis, é "Representações da mulher que joga futebol". O trabalho foi orientado por Sebastião Josué Votre, na Universidade Gama Filho - RJ.
} 
Outro fator que pode explicar o aumento no número de estudos a partir de 2008 é a criação da Revista Brasileira de Futsal e Futebol (RBFF) no ano de 2009. De acordo com os resultados apresentados na Tabela 1, a RBFF é a revista com o maior número de publicações sobre futebol e futsal feminino entre os periódicos nacionais, responsável por $18 \%$ das publicações sobre as modalidades. A RBFF publica estudos de professores, estudantes e profissionais que trabalham com futebol e futsal no âmbito da iniciação ao alto rendimento, abordando questões pedagógicas, sociais e de treinamento. Entretanto, é importante lembrar que os estudos sobre futebol e futsal feminino representam menos de $4 \%$ de todos os artigos publicados pela RBFF.

Assim como a RBFF, diversos periódicos nacionais relacionados à Educação Física foram criados na última década. Para Galatti et al. (2016), esse fator pode explicar o aumento de publicações sobre outro tema esportivo, treinadores, verificado pelos autores a partir de 2008. Da mesma forma, esse fato também pode ter contribuído para o aumento de publicações nacionais sobre futebol feminino.

Dentro da categoria "gênero" encontramos uma grande quantidade de artigos que abordam o futebol e futsal feminino na Educação Física Escolar. O início dos anos 1990 marcou um debate nesta área a respeito da divisão entre meninos e meninas nas aulas de Educação Física, separação esta que era resultado de algumas concepções marcadas pela dicotomia feminino e masculino, apontando, sobretudo, as diferenças biológicas na prática das atividades (JACÓ; ALTMANN, 2017). Embora existam contemporaneamente diversas possibilidades para se pensar o corpo e o movimento nas aulas de Educação Física, ainda fica evidente o despreparo dos professores em produzir conteúdos que não se valham dessa dicotomia e que permitam 0 aprendizado igualitário de meninas e meninos (UCHOGA; ALTMANN,2016). Foi a partir dessas tensões provenientes das aulas mistas que a categoria gênero começou a povoar os estudos da Educação Física Escolar, futebol e futsal, conteúdos recorrentes nas escolas brasileiras.

Os debates sobre os temas gênero e Educação Física Escolar que ocorrem há duas décadas foram fundamentais para possibilitar e fomentar a prática do futebol e do futsal feminino no ambiente escolar. Diversos estudos mostram que, apesar da prática ainda ser majoritariamente masculina, as meninas começam a conquistar seu espaço e praticaras modalidades dentro das escolas (JÚNIOR; DARIDO, 2002; BASTOS; NAVARRO, 2009; KERNE, 2014). É evidente que o aumento das publicações a partir do fim da década de 2010 reflete os debates que começaram a ser elaborados a respeito dessas diferenças e os embates de gênero no ambiente escolar, e é evidente também que essas reflexões permitem transformações que empoderam ${ }^{9}$ as meninas praticantes de esportes e que passam a frequentar outros ambientes esportivos com mais desenvoltura (ALTMANN, 2017).

Em contrapartida, encontramos poucos estudos sobre as questões técnicas, táticas e físicas dos esportes analisados - futebol e futsal- discussão igualmente importante para 0 desenvolvimento das modalidades. 0 conhecimento sobre as características das partidas femininas é fundamental para capacitar os profissionais que irão trabalhar com o futebol e 0 futsal feminino. $O$ amadorismo ainda existente nas modalidades, assim como os poucos profissionais contratados pelas equipes nacionais e a baixa disponibilidade de materiais para o treinamento, provavelmente dificulta a produção de dados técnicos e, consequentemente,

9 Para Altmann (2017), as meninas são empoderadas, ou seja, são capazes de reivindicar por direitos iguais no campo esportivo quando são dotadas de capacidades técnicas e táticas nos esportes. Isso significa que um professor de Educação Física Escolar pode dar poder a estas 
de trabalhos acadêmicos. Além disso, a menor quantidade de artigos sobre treinamento provavelmente reflete a discriminação e menor aceitação das publicações de mulheres que dissertam sobre essa temática (SOUZA; CAPRARO; JENSEN, 2017).

Neste trabalho verificamos uma quantidade próxima de homens e mulheres como primeiros autores nos artigos sobre futebol e futsal feminino, como mostrado na Tabela 2. Já em relação aos coautores, verificamos uma maior presença de homens (Tabela 2). Um dos artigos encontrados, "Pesquisadoras do futebol: discussões a partir de duas trajetórias" (ANJOS; DANTAS, 2016), investigou a presença das mulheres no universo das pesquisas sobre futebol, principalmente em relação àquelas que não pesquisam temáticas relacionadas às discussões sobre gênero como elemento central em seus trabalhos. Nas trajetórias das duas escritoras entrevistadas foi verificado que a participação feminina em estudos de gênero tem maior aceitação e visibilidade no Brasil, enquanto que ao escreverem sobre outras temáticas são vistas com processos de estranhamento e desconfiança por serem mulheres. Outro artigo encontrado, "Mulheres fora da área: escritoras arriscando-se a dissertar sobre futebol" (SOUZA; CAPRARO; JENSEN, 2017), teve como objetivo apresentar reflexões sobre o número reduzido de literatas que escreveram sobre futebol, possibilitando também refletir sobre o domínio masculino perpetuado nessa esfera. 0 estudo mostrou que as mulheres escritoras, quando não se desculparam por estar escrevendo sobre tal temática, procuraram se afastar de avaliações técnicas ou táticas da partida. Nesse sentido, apontamos a importância de as mulheres avançarem com a discussão sobre o futebol feminino e também assumirem debates tradicionalmente realizados apenas por homens.

Além do preconceito sofrido pelas escritoras, o aspecto prático também pode ajudar a explicar o aparente menor interesse das mulheres pelos temas mais próximos ao treinamento: a dificuldade de inserção feminina nos clubes de futebol como treinadoras, como, por exemplo, a recente e rápida passagem de Emily Lima como a primeira treinadora a assumir uma seleção brasileira principal. Observamos também poucas treinadoras à frente das equipes femininas nos clubes e em times amadores (VARGAS; CAPUTO; SILVA, 2017). Esse distanciamento do acesso prático ao treinamento pode diminuir o interesse imediato por esse campo de pesquisa e, por outro lado, impulsionar o interesse às questões de gênero.

No nosso estudo buscamos mapear a produção científica nacional sobre futebol e futsal feminino. Como limitações do método utilizado, é importante destacar que foram analisados somente trabalhos publicados em periódicos nacionais. Portanto, monografias, dissertações e teses não foram incluídas neste estudo. Além disso, artigos de pesquisadores brasileiros publicados em revistas internacionais, ou em revistas indexadas em outras áreas, também não foram considerados, reforçando que há mais estudos sendo realizados no país além dos apresentados neste trabalho.

\section{CONSIDERAÇÕES FINAIS}

Neste estudo analisamos a produção acadêmica sobre o futebol e futsal feminino nos periódicos nacionais de Educação Física. Os resultados aqui encontrados dialogam com diversos acontecimentos relacionados às modalidades fora do campo científico. Os primeiros estudos sobre futebol e futsal feminino foram publicados no final da década de 1990, período em que as mulheres não são mais proibidas de praticarem as modalidades e em que a seleção 
brasileira de futebol feminino participa da primeira edição da Copa do Mundo de Futebol Feminino (1991) e da estreia da modalidade nos Jogos Olímpicos (1996).

O grande aumento da produção científica nacional ocorreu a partir de 2008 em função de diversos acontecimentos no campo esportivo e acadêmico. Os anos 2000 são marcados pela maior visibilidade dada ao futebol feminino pela mídia em decorrência do bom desempenho da seleção principal brasileira nos Jogos Olímpicos (2004 e 2008), na Copa do Mundo de Futebol Feminino (2007), e nos Jogos Pan-Americanos (2007). Essa década também é marcada pela crescente discussão sobre gênero, esporte e Educação Física Escolar. Durante esse período também foi criada a Revista Brasileira de Futsal e Futebol, principal veículo de publicação e divulgação de estudos nacionais relacionados ao futebol e ao futsal feminino.

Verificamos que os estudos de gênero representam, aproximadamente, um terço de toda a publicação sobre futebol e futsal feminino em periódicos nacionais de Educação Física. Esse resultado reflete a necessidade do debate sobre gênero para reverter um cenário esportivo marcado por preconceitos e desafios.

Assim, esse levantamento, longe de esgotar as possibilidades de compreensão sobre o estado da arte do futebol feminino na área 21, nos ajuda a pensar a forma como se deu a produção de conhecimento sobre futebol e futsal feminino até o presente momento, além de mapear os artigos científicos que se debruçam sobre essas temáticas. Procuramos, assim, auxiliar os pesquisadores a compreender como esse campo de conhecimento se estruturou ao longo das últimas décadas e como ele pode ser explorado por estudos futuros.

\section{REFERÊNCIAS}

ALTMANN, Helena. Atividades físicas e esportivas e Mulheres no Brasil. In: Relatório Nacional de Desenvolvimento Humano do Brasil. Brasília: Teixeira Gráfica, 2017. p. 1-36.

ANJOS, Luiza Aguiar; DANTAS, Marina Mattos. Pesquisadoras do futebol: discussões a partir de duas trajetórias. Esporte e Sociedade, n. 28, p. 1-28, 2016.

BASTOS, Paula Viotti; NAVARRO, Antonio Coppi. O futsal feminino escolar. Revista Brasileira de Futsal e Futebol, v.1, n.2, p.144-162, 2009.

BRASIL. Conselho Nacional de Desportos. Deliberação n. 7 de agosto de 1965. Disponível em: <www.planalto.gov.br $>$. Acesso em: 8 nov.2014.

BRASIL. Conselho Nacional de Desportos. Normas básicas sobre desportos. Deliberações. Rio de Janeiro, 1979.

BRASIL. Ministério do Esporte. A prática do esporte no Brasil. Brasília, DF, 2013. Disponível em: <www.esporte.gov.br/diesporte/2.html>. Acesso em: 3 fev.2017.

DATSON, Naomi et al. Applied physiology of female soccer: an update. Sports Medicine, v. 44, n. 9, p. 1225-1240, 2014.

FELTRIN, Murilo Bortolotti et al. Caracterização de praticantes de futebol feminino no Brasil. 
FERREIRA, Norma Sandra de Almeida. As pesquisas denominadas estado da arte. Educação \& Sociedade, v. 23, p. 257- 272, 2002.

GALATTI, Larissa et al. Coaching in Brazil Sport Coaching as a Profession in Brazil: an Analysis of the Coaching Literature in Brazil From 2000-2015. International Sport Coaching Journal, v. 3, n. 3, p. 316-331, 2016.

GOELLNER, Silvana Vilodre. Mulheres e futebol no Brasil: entre sombras e visibilidades.

Revista Brasileira de Educação Física e Esporte, v. 19, n. 2, p. 143-151, 2005.

JACÓ, Juliana Fagundes; ALTMANN, Helena. Significados e expectativas de gênero: olhares sobre a participação nas aulas de educação física. Educação em Foco, v. 22, p. 1-26, 2017.

JÚNIOR, Osmar Moreira de Souza; DARIDO, Suraya Cristina. A prática do futebol feminino no Ensino fundamental. Motriz, v. 8, n. 1, p.1-9, 2002.

KERNE, Felipe. Futebol feminino na escola na perspectiva de alunas do ensino fundamental.

Revista Brasileira de Futsal e Futebol, v.6, n. 22, p.278-284, 2014.

MOURÃO, Ludmila; MOREL, Marcia. As narrativas sobre o futebol feminino o discurso da mídia impressa em campo. Revista Brasileira de Ciências do Esporte, v. 26, n. 2, p. 73-86, 2008.

REIS, Lucia da Costa Leite. Representações da mulher que joga futebol. 1997. $127 f$.

Dissertação (Mestrado em Educação Física) - Universidade Gama Filho, Rio de Janeiro, 1997.

SALLES-COSTA, Rosana et al. Gênero e prática de atividade física de lazer. Cadernos de Saúde Pública, v.19, n. 2, p.S325-S333, 2003.

SALVINI, Leila; FERREIRA, Ana Letícia Padeski; MARCHI JÚNIOR, Wanderley. O futebol feminino no campo acadêmico brasileiro: mapeamento de teses e dissertações (1990 - 2000).

Pensar a Prática, v. 17, n. 4, p. 1-14, 2014.

SOUSA, Eustáquia Salvadora de; ALTMANN, Helena. Meninos e meninas: expectativas corporais e implicações na educação física escolar. Cadernos Cedes, v.19, n. 48, p. 52-68, 1999.

SOUZA, Juliana Sturmer Soares; KNIJNIK, Jorge Dorfman. A mulher invisível: gênero e esporte em um dos maiores jornais diários do Brasil. Revista Brasileira de Educação Física e Esporte, v. 21, n. 1, p. 35-48, 2007.

SOUZA, Maria Thereza Oliveira; CAPRARO, André Mendes; JENSEN, Larissa. Mulheres fora da área: escritoras "arriscando-se" a dissertar sobre futebol. Motrivivência, v. 29, n. 50, p.140152, 2017.

TEIXEIRA, Fábio Luís Santos; CAMINHA, Iraquitan de Oliveira. Preconceito no futebol feminino brasileiro: uma revisão sistemática. Movimento, v. 19, n. 1, p. 265-287, 2013.

TEIXEIRA, Luis Augusto et al. Assimetrias laterais no desempenho de habilidades motoras relacionadas ao futebol. Kinesis, n. 20, p. 77-92, 1998.

UCHOGA, Liane Aparecida Roveran; ALTMANN, Helena. Educação física escolar e relações de gênero: diferentes modos de participar e arriscar-se nos conteúdos de aula. Revista Brasileira de Ciências do Esporte, v. 38, n. 2, p. 163-170, 2016.

VARGAS, Laís de Freitas; CAPUTO, Eduardo Lucia; SILVA, Marcelo Cozzensa. Caracterização do perfil dos treinadores de futsal feminino de equipes que disputam os jogos abertos de Pelotas. Revista Brasileira de Futsal e Futebol, v. 9, n. 33, p. 151-159, 2017. 
VIANA, Aline Edwiges dos S. Futebol: das Questões de Gênero à Prática Pedagógica.

Conexões, v. 6, ed. especial, p. 640-648, 2008. 